\section{The management of traumatic tooth loss with dental implants: Part 2. Severe trauma}

\author{
D. W. Seymour, ${ }^{* 1}$ M. Patel, ${ }^{2}$ L. Carter ${ }^{3}$ and M. Chan ${ }^{2}$
}
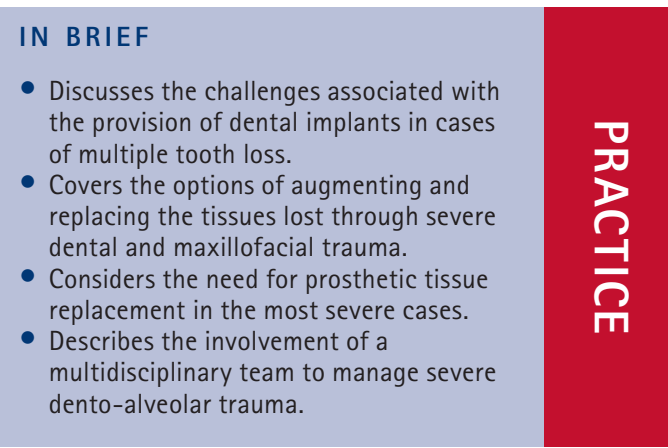

In part 2 of this series, we look at the clinician's role in replacing multiple missing teeth and the associated soft tissues and bone, following severe forms of trauma. These patients usually wish to have fixed prostheses to help restore their appearance and function. In order to fulfil the patient's request, the multidisciplinary team can be faced with significant challenges, often requiring extensive reconstructive surgery and complex implant oral rehabilitation. The aim of this paper is to highlight to the general dental practitioner some of the challenges faced in rehabilitating severe trauma patients with implant retained prosthesis. By understanding the challenges it is hoped that the general dental practitioner will be able to make an assessment of the clinical situation and seek appropriate specialist advice to ensure optimal results for their patients. In the longer term, the management of these patients requires a shared care approach between the general dental practitioner and relevant specialists.

\section{RESTORATIVE CHALLENGES OF SEVERE TRAUMA}

Severe trauma can result in significant loss of teeth and associated soft and hard tissues (Figs 1a-c). Often the teeth that remain show signs of significant damage and may be unrestorable. Others may have been luxated or avulsed and subsequently re-implanted, which can result in a compromised longterm prognosis.

The simplest solution is often to provide a removable partial denture, which can replace not only the teeth, but also the missing hard and soft tissues in the form of a pink acrylic flange. However, problems with support and retention can lead to functional problems and discomfort. Many patients are reluctant to accept a removable prosthesis and often seek a fixed solution. Large edentulous spans may rule out any form of conventional bridgework for these patients leaving dental implants as the only predictable fixed option.

Following a significant traumatic injury patients often present with fractures of the facial complex. Multiple techniques exist

${ }^{1}$ Speciality Registrar in Restorative Dentistry, ${ }^{2}$ Consultant, Restorative Dentistry, ${ }^{3}$ Consultant, Oral and Maxillofacial Surgery, Leeds Dental Institute, Clarendon Way, Leeds, LS2 9LU

*Correspondence to: Mr David Seymour

Email:dwseymour@hotmail.co.uk

\section{Refereed Paper}

Accepted 5 September 2014

DOI: 10.1038/sj.bdj.2014.1102

${ }^{\circledR}$ British Dental Journal 2014; 217: 667-671

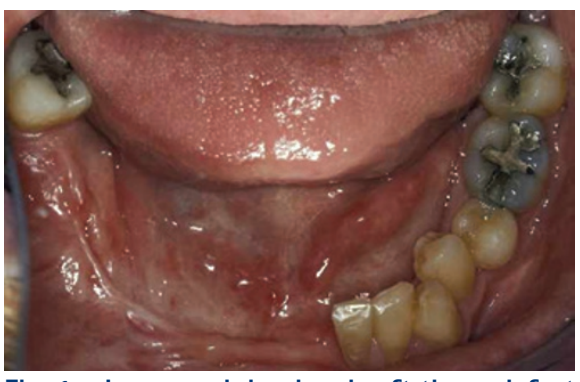

Fig. 1a Lower arch hard and soft tissue defect

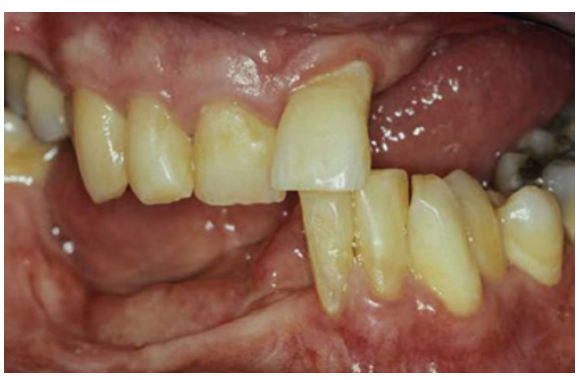

Fig. 1c Compromised prognosis 21, 31, 32 following luxation

to repair the bony injury depending on its site and severity. ${ }^{1}$ The most common technique in the UK today is open reduction and internal fixation (ORIF). The use of titanium mini-plates/plates, screws and reconstruction plates are widely used (Fig. 1d). The metal plates, intra-osseous screws and wires can cause an imaging problem or obstruct implant placement. Current use of cone beam computed tomography (CBCT) and associated software has reduced imaging problems; however, the placement of implants in plated

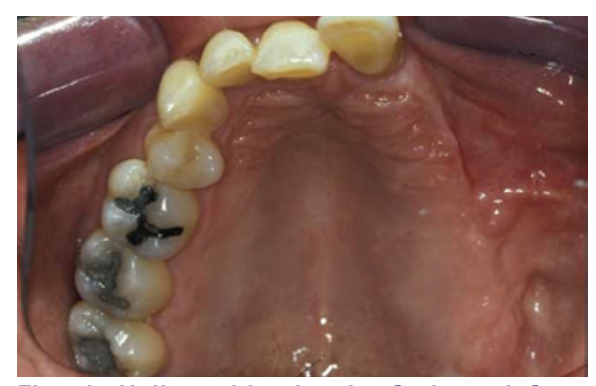

Fig. 1b Unilateral hard and soft tissue defect

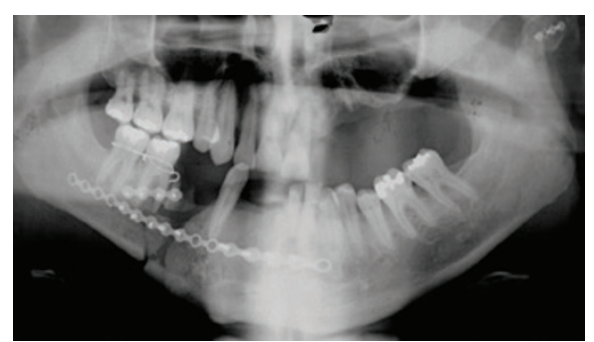

Fig. 1d Multiple complex fractures of the maxillofacial region caused by a severe road traffic accident

bone continues to present the clinician with a challenge. The options are:

1. Removal of either the offending screw or the whole plate and screws

- This option is only possible once bony union of the fracture has been established. This procedure may be contra-indicated due to surgical difficulties surrounding the removal of the plate. Decisions need to be made on a case by case basis in conjunction with the maxillofacial team. 
2. Placement of implants beside/in between screws

- Computed tomography data can be used by the clinician to plan the ideal position for implants preoperatively. From this data stereolithographic models can be produced and surgical stents fabricated to guide the preparation of the osteotomy sites to precisely fit around screws or plates. While these techniques may help a clinician during the placement of implants they should not be considered a replacement for traditional planning as studies have shown that the final implant position may differ from the planned position. ${ }^{2,3}$

\section{BONE DEFECTS}

Tooth loss results in changes to the bony architecture of the alveolar ridge. ${ }^{4}$ Alveolar bone requires stimulation via the periodontal ligament to maintain its volume; ${ }^{5}$ once this is lost there is a change in the composition of bone in the area leading to a decrease in bone height and width. When multiple teeth are lost this change in bone volume can be marked and when multiple teeth are traumatically avulsed/luxated bone loss is often exacerbated.

\section{ASSESSING CASES FOR BONE LOSS AND GRAFTING}

Appropriate clinical and radiographic assessment is important to identify whether bone grafting is needed to facilitate implant placement and the type of grafting procedure that is most appropriate (Fig. 2). This is essential to ensure there is sufficient bone in the correct position for ideal implant placement. The ideal tooth position should be defined initially by using either a diagnostic wax-up or a trial denture set-up depending on the number of teeth missing and the clinician's preference. Tooth position is dependent upon functional and aesthetic considerations and should be agreed with the patient. CBCT is usually employed, using software programmes to give high quality cross sectional images. ${ }^{6}$ Radiographic stents are worn by the patient during the imaging procedure to relate the required tooth position to the bone available (Fig. 2). The most common stent used is an acrylic stent with radiographic markers on the buccal aspect of the prosthetic tooth ${ }^{7}$ or alternatively radio-opaque teeth may be used as the markers.

Where multiple teeth and significant soft and hard tissue have been lost, block bone grafting techniques need to be considered. Various intra-oral and extra-oral grafting

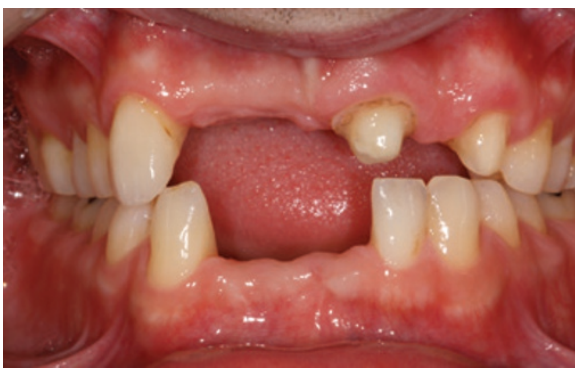

Fig. 2a Hard and soft tissue defects in the anterior region following a cricket ball injury

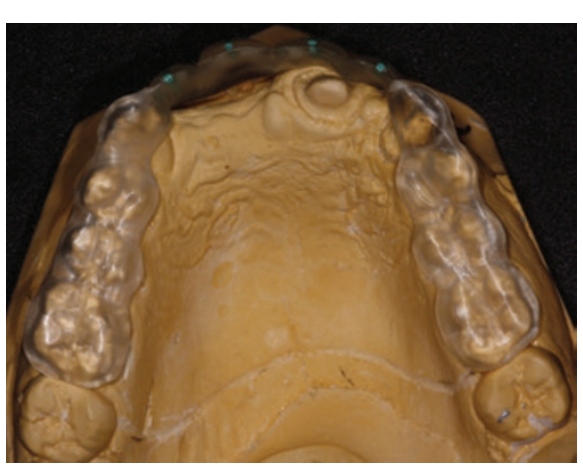

Fig. 2b Radiographic/surgical guide reproducing tooth position determined from diagnostic wax up

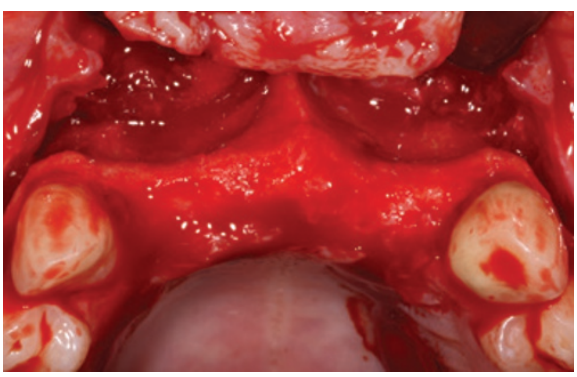

Fig. 2c Extent of buccal bone loss following traumatic loss of teeth and extraction of 21

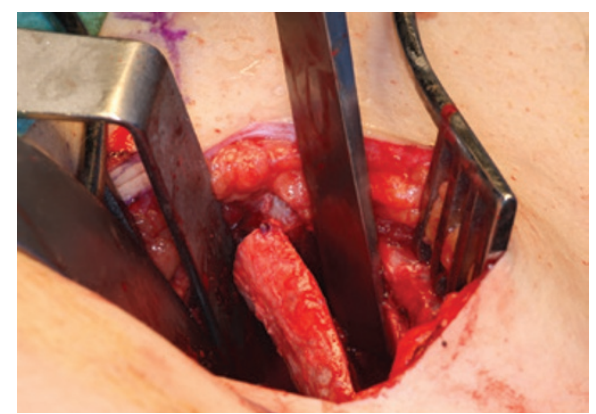

Fig. 2d The iliac crest is exposed and the bone marked to represent the dimensions of bone required. The bone is sectioned using a surgical saw and harvested

techniques have been described in the literature to graft alveolar bone to allow implant placement.

\section{INTRA-ORAL GRAFTING PROCEDURES}

Bony defects are generally classified as horizontal, vertical or both. In cases of extensive bone loss a two-stage procedure using block

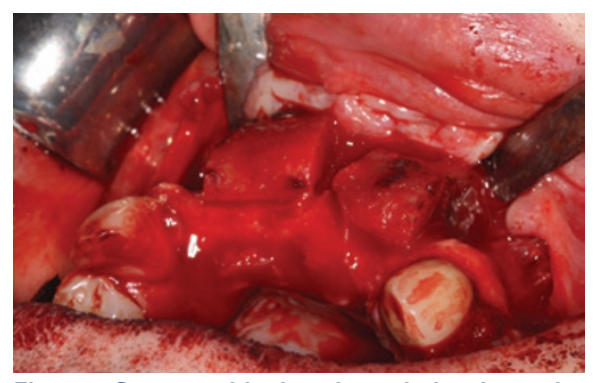

Fig. 2e Separate blocks adapted closely to the recipient site and secured with mini-screws. This is to ensure good bony healing

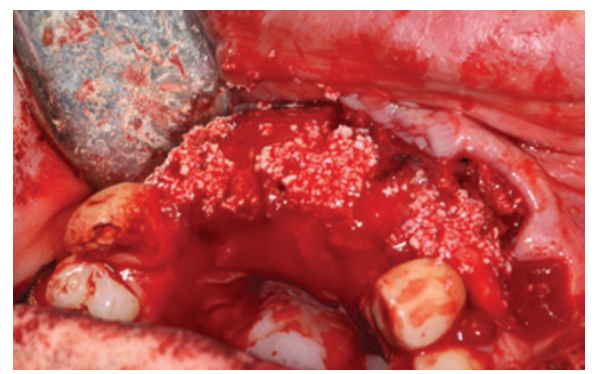

Fig. 2f Packing particulate bone in to the gaps around the block graft. A mixture of autogeneous bone and bovine bone mineral particulate

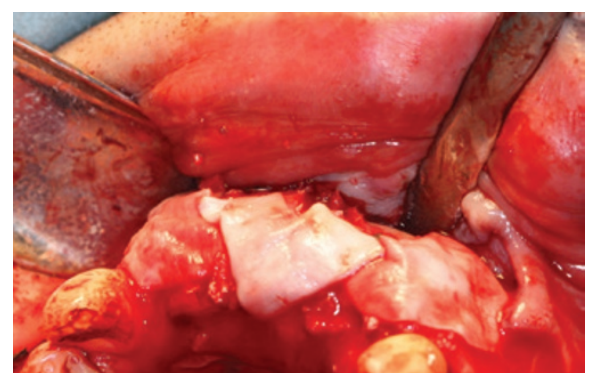

Fig. $2 \mathrm{~g}$ Placement of a porcine collagen membrane over the bone graft to prevent soft tissue invasion

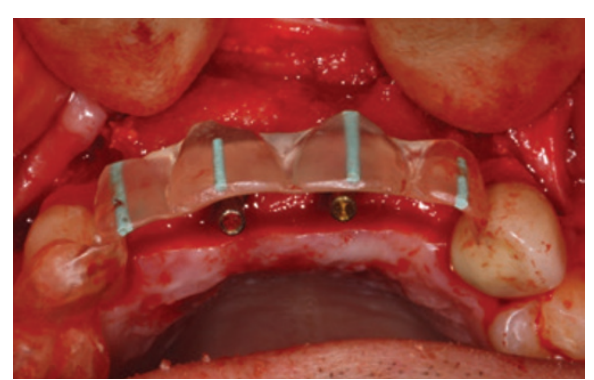

Fig. $2 \mathrm{~h}$ Implant placement after four months healing of the block graft. Implants can be placed in the ideal position determined by the guide for a screw retained prosthesis

bone grafts and delayed implant placement is often indicated. ${ }^{8}$ Autogenous graft sites to repair horizontal defects include the mandibular symphasis, ${ }^{9}$ body of the ramus ${ }^{10}$ and the maxillary tuberosity. ${ }^{11}$ While much work comparing the success/survival of implants placed in horizontal grafts to standard sites has been completed, ${ }^{8,12}$ a consensus report on bone augmentation procedures before 


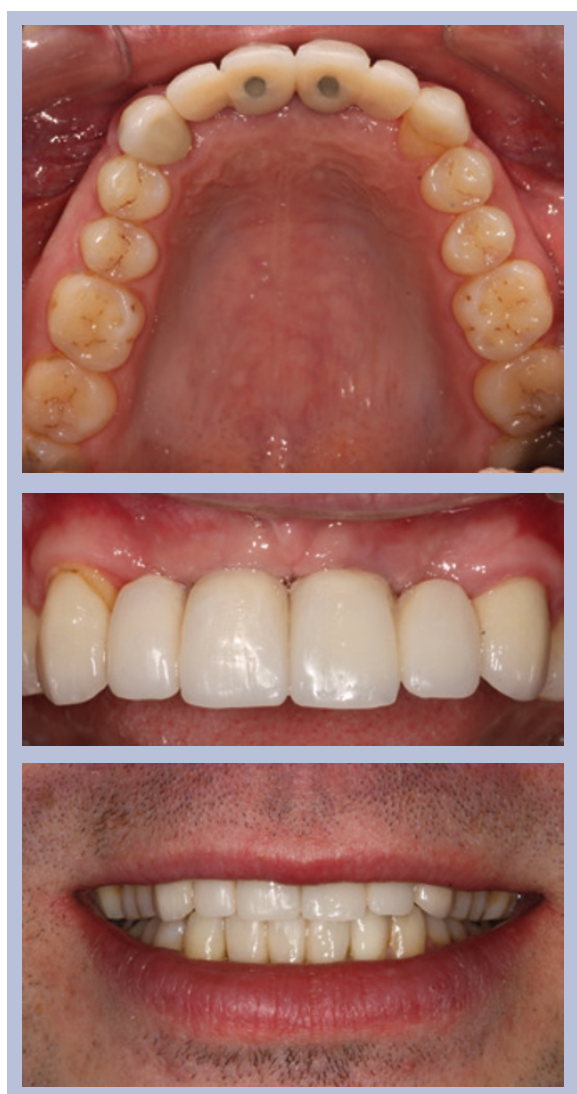

Figs 2i-k Provisional screw retained restorations in situ highlighting ideal implant and tooth positioning for this patient

implant placement ${ }^{13}$ states that there is currently not enough evidence to conclusively compare the two procedures.

Vertical bone defects present a more complex problem to the clinician. The management of such defects is a contentious issue. The intra-oral techniques available to the clinician generally speaking include block onlay bone grafting and distraction osteogenesis. Work by Rocchietta et al. ${ }^{14}$ looked at the predictability of the above procedures and while the procedures showed promise, Tonetti et al. ${ }^{13}$ explained that the evidence for block onlay grafts and distraction osteogenesis in vertical defects is limited. Vertical bone augmentation in the posterior maxilla involving bone grafting into the maxillary sinus has been shown to be a predictable solution allowing subsequent implant placement with good success rates..$^{15}$ It is generally accepted that most other forms of vertical bone augmentation are extremely difficult and highly unpredictable. ${ }^{16}$

\section{EXTRA-ORAL BONE GRAFTING}

The bone available from the common intra-oral donor sites is finite, and often not enough to graft sites of extensive trauma with multiple missing teeth. Extraoral sites offer larger bone volumes and are commonly used. A systematic review by Chiapasco et al. ${ }^{8}$ investigating bone

\section{Table 1 Advantages and disadvantages on iliac crest block onlay graft}

\begin{tabular}{|l|l|}
\hline Advantages of iliac crest & Disadvantages of Iliac crest \\
\hline Osteogenic potential & $\begin{array}{l}\text { Cortico-cancellous endochondral bone therefore } \\
\text { revascularises slowly and resorbs more rapidly } \\
\text { compared to intraoral intramembranous block grafts } \\
\text { with more cortical bone }\end{array}$ \\
\hline Relatively easy to harvest & Donor site morbidity \\
\hline $\begin{array}{l}\text { Harvest large bone volume to correct large defects } \\
\text { and restore ridge form }\end{array}$ & $\begin{array}{l}\text { Difficulty in managing soft tissues for primary } \\
\text { closure }\end{array}$ \\
\hline Simultaneous surgery at recipient site and donor site & Longer treatment time \\
\hline
\end{tabular}

augmentation procedures showed that the iliac crest was the most common site used extra-orally. Advantages and disadvantages of the iliac crest block onlay graft are shown in Table 1.

Reconstruction following severe head and neck trauma very rarely may take the form of vascularised free flaps to restore the hard/ soft tissue defects. The principles of restoring these defects using dental implants is similar to the treatment of post-oncologic defects. The literature surrounding the survival/success rates of implants in free flaps is not robust. A systematic review by Barber et al. ${ }^{17}$ showed a survival rate of $96-100 \%$ with a follow-up period between 15-96 months. It is worth noting that the authors recognised that there was no form of randomisation in all but one of the articles and only two of the studies were prospective. Chiapasco et al. ${ }^{8}$ found a lower survival rate of $72 \%$, however, this was based on the placement of 17 implants only.

Advantages of using a free flap include a low level of bone resorption pre- and post-implant placement. There is also surgical freedom regarding the positioning of the bone. There are multiple surgical disadvantages including increased surgical time, morbidity, costs and the length of time spent in hospital as an in-patient. The primary difficulty regarding dental implant restoration is the management of the soft tissues in both the short and the long term.

\section{SOFT TISSUE DEFECT}

Soft tissue defects can pose a significant challenge to the clinician, especially in the upper anterior region, in a patient with a high smile line. The loss of multiple teeth can have a serious impact on the position and morphology of the soft tissues. The morphology of the soft tissues is related to the underlying bone, tooth position, tooth angulation and gingival biotype. Soft tissue management should therefore begin from the time teeth are lost. Failure to manage the soft tissues appropriately can lead to both an aesthetic and functional failure of the final implant retained prosthesis. The most common problem encountered when multiple teeth are lost is the vertical soft tissue defect and the loss of the interdental papillae. Creating inter-dental papillae when multiple teeth are missing is a challenge to the clinician. This is especially difficult when tooth loss is asymmetrical: replicating the contra-lateral soft tissue aesthetics is often the key to a successful aesthetic outcome.

General soft tissue management techniques from the time of tooth loss may include:

\section{At time of extracting the fractured/traumatised teeth}

Removal and thorough surgical cleaning of any remaining tooth fragments/foreign bodies at the site of the wound is important. Failure to do so could compromise healing in the area or lead to infection which can result in further bone loss and soft tissue deterioration.

Often a partial denture is fitted and the design of this prosthesis is also important. The saddle should not be socket fitted and should place minimal pressure on the edentulous ridge. ${ }^{18}$ The denture should be hygienic and easily cleansable.

\section{At time of implant placement or second stage surgery}

Often when a lack of keratinised tissue is identified a connective tissue graft can be carried out. The use of a connective tissue graft harvested from the palate to improve soft tissue aesthetics has been shown to be relatively stable when performed at the time of second stage surgery ${ }^{19}$ and various techniques have been described for this surgical procedure. ${ }^{20}$

In some cases this may be carried out as a separate surgical intervention in between implant placement and second stage surgery to expose the implant.

\section{At time of abutment placement}

Traditionally abutment stage surgery has consisted of a punch technique or a minimal linear incision. In a large number of trauma cases manipulation of the soft tissues around the 
healing abutment at the time of surgery allows optimal tissue healing. ${ }^{21}$ Palacci described the use of a rotated paedicle flap of soft tissue into the interdental region to restore the papilla in a technique widely known as a Palacci flap..$^{22}$ The technique is now commonly used. The keys to successful use of the technique as described by Palacci are:

1. Careful handling of the tissues to maximise vascularisation

2. Bevel incisions in the mobile flap should be delicate and vary according to needs

3. The rotated paedicles should be tension free

4. The suturing technique should provide a tight and firm connection of the paedicles to the supporting bone and abutments.

\section{Soft tissue surgery following restoration of the implant}

Connective tissue and free gingival grafts are a viable option when augmenting soft tissue defects (that is, recession defects) in natural teeth. ${ }^{23,24}$ However, the use of such techniques has been shown to be unpredictable when used around restored implants. ${ }^{25}$ It should therefore be the clinicians aim to consolidate soft tissue aesthetics before definitive restoration.

When faced with large hard tissue defects it may not be possible to surgically correct the lost soft tissue. Prosthodontic rehabilitation of the lost soft tissue may take the form of pink porcelain, composite or acrylic (Fig. 3).

\section{COMPLEX TRAUMA}

Severe facial trauma can result in a large skeletal and occlusal discrepancy which can make oral rehabilitation very difficult. Management of these patients often requires detailed planning with input from orthodontists and maxillofacial surgeons. Multiple stages comprising of fixed appliance orthodontic therapy, orthognathic surgery, bone grafting, surgical implant placement and prosthetic rehabilitation may be indicated. The detailed discussion of the various permutations possible in these cases is beyond the scope of this paper. It is important to highlight that despite the best efforts of the multidisciplinary team, the final outcome for patients with very complex trauma can be significantly compromised. In these severe cases a removable prosthesis can be used to disguise the extent of large hard and soft tissue defects as well as adverse skeletal relationships (Fig. 4).

\section{MAINTENANCE}

Plaque induced peri-implant mucositis ${ }^{26}$ and peri-implantitis ${ }^{27}$ are well documented

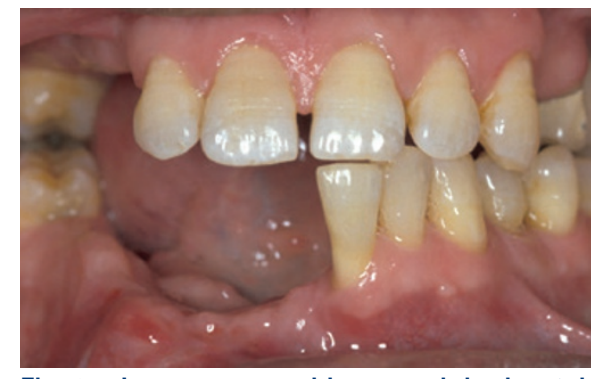

Fig. 3a Large upper and lower arch horizontal and vertical bony defects following trauma from an industrial accident

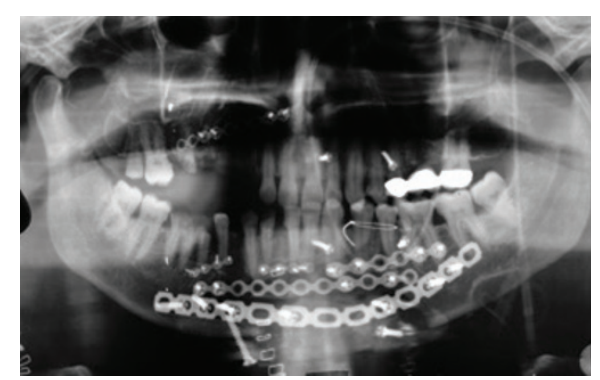

Fig. 3b Complex trauma reconstruction

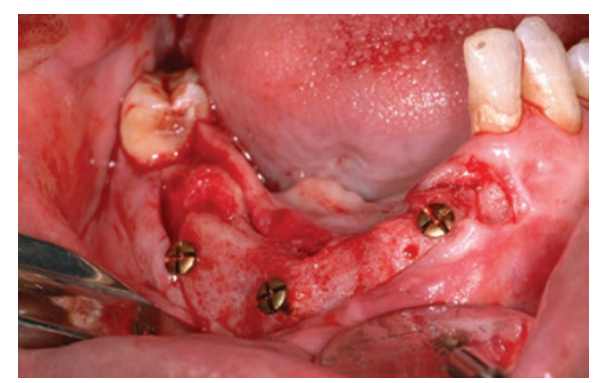

Fig. 3c Iliac crest block onlay graft to increase the bucco-lingual bone volume to allow implant placement at strategically selected sites

disease processes that can affect the longterm stability of osseointegrated dental implants. Although there is no accepted treatment strategy for established periimplantitis, it is agreed that self-administered oral hygiene practices to maintain soft tissue health should be implemented by all implant patients. ${ }^{28}$ The design of the overlying prosthesis plays a key role and should allow the patient access to practise oral hygiene measures unhindered. The clinician also has an obligation to thoroughly demonstrate these techniques to the patient. The patient's compliance should be monitored regularly to ensure the long-term health of the peri-implant tissues. Retrievable screw retained prostheses allows subsequent maintenance, repair or replacement far simpler compared to cemented prostheses and should be the prosthesis of choice.

\section{DISCUSSION}

Rehabilitating patients who have had severe dentofacial trauma can be challenging. Careful planning is required to assess the
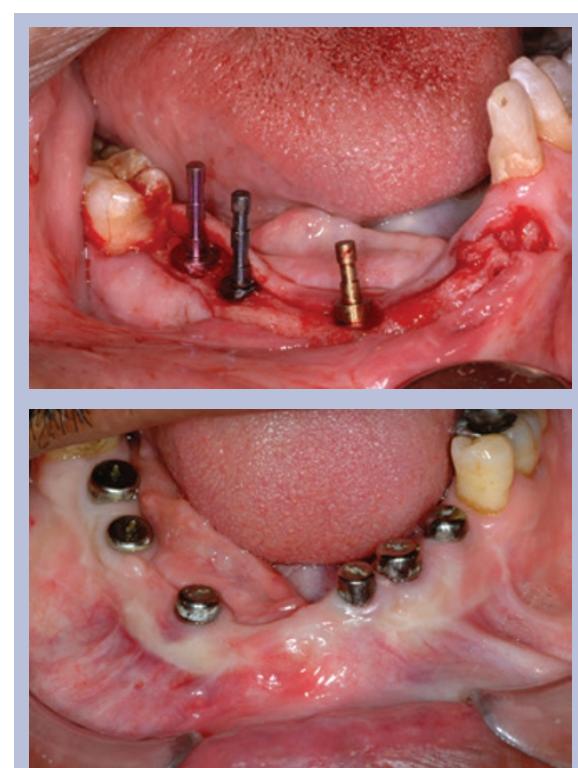

Figs 3d-e Six implants were placed under local anaesthetic into ideal positions for a screw retained prosthesis

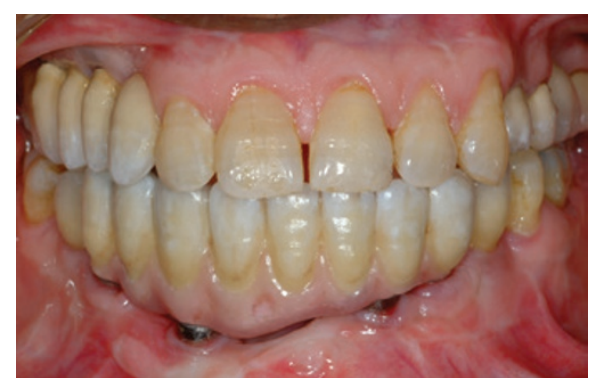

Fig. 3f Definitive prosthesis in situ in both the upper and lower arch

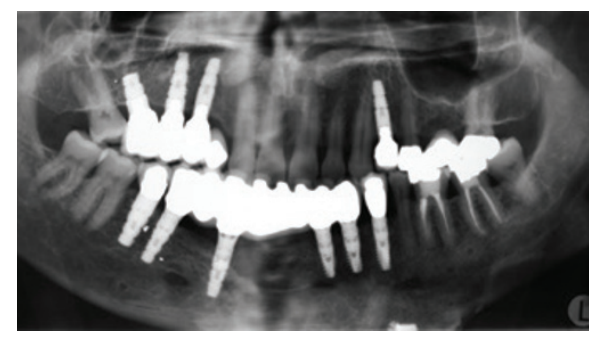

Fig. 3g OPG showing definitive prosthesis in situ

prognosis of the remaining teeth, the bone volume available, the position of the available bone in relation to the proposed final restorations, the amount of keratinised soft tissue present and occlusal relationships. In many severe trauma patients the bone is lacking and augmentation is required to facilitate implant placement. In some cases unfavourably placed healthy teeth may need to be sacrificed to allow rehabilitation and the use of the bone around the extraction site for implant placement. In other cases bone grafting is required and where a large block of bone is planned, the iliac crest is often a good donor site for the reasons outlined in Table 1 . The clinical 


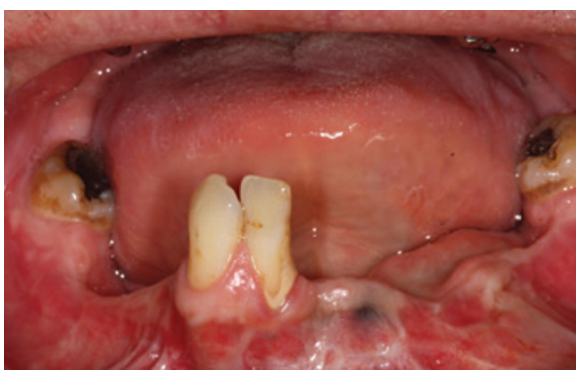

Fig. 4a Severe trauma following a fall

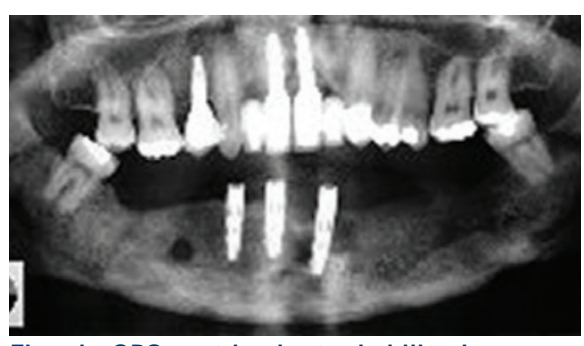

Fig. 4b OPG post implant rehabilitation

techniques outlined in this paper for the grafting procedure can result in a predictable outcome. Timely implant placement into successfully grafted bone is essential along with possible soft tissue grafting to ensure the bone does not resorb away and that healthy peri-implant tissues are maintained. The design of the final prosthesis plays a vital role in the overall aesthetic appearance of the rehabilitation; however, it is essential that whatever prosthesis is provided, good oral hygiene can be maintained on a daily basis by the patient. Ultimately, this will determine the long-term success and survival of the rehabilitation.

The authors would like to acknowledge all the laboratory and clinical staff at the Leeds Dental Institute who have contributed to the care of the patients shown in these articles, and in particular $\mathrm{Mr}$ K. Wilson for most of the technical work shown, and $\mathrm{Mr}$ J. Chesterman for his assistance with the referencing and submission of manuscript. Finally, some of the cases presented in this paper were presented in a poster at the ADI $25^{\text {th }}$ anniversary team congress meeting in Manchester and awarded the poster presentation prize.

1. Motamedi M H K. An assessment of maxillofacial fractures: a five-year study of 237 patients. J Oral Maxillofac Surg 2003; 61: 61-64.

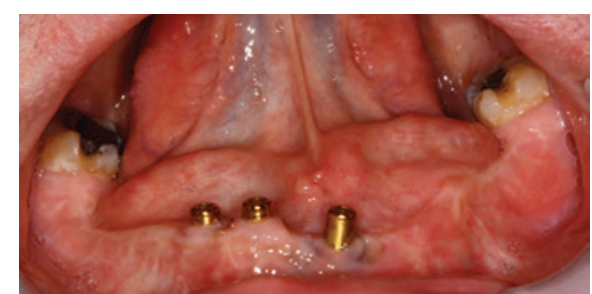

Fig. 4c Locator $^{\circledR}$ attachments in situ

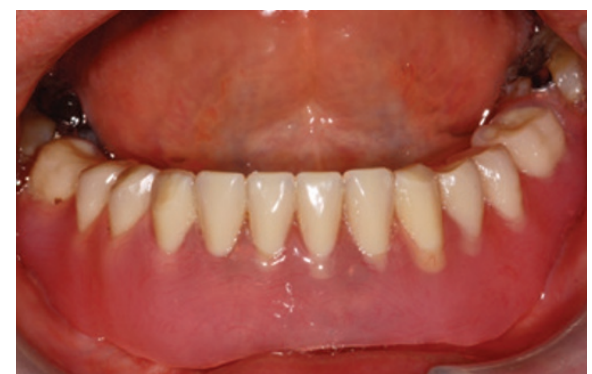

Fig. 4d Lower implant over denture in situ

2. Schneider $D$, Marquardt $P$, Zwahlen $M$, Jung $R E$. A systematic review on the accuracy and the clinical outcome of computer-guidedtemplate-based implant dentistry. Clin Oral Implants Res 2009; 20(Suppl 4): 73-86.

3. Tahmaseb A, Wismeijer D, Coucke W, Derksen W. Computer technology applications in surgical implant dentistry: a systematic review. Int J Oral Maxillofac Implants 2014; 29 (Suppl): 25-42.

4. Roberts W E, Turley P K, Brezniak N, Fielder P J. Bone physiology and metabolism. CDA J 1987; 15: 54-61.

5. Pietrokovski J. The bony residual ridge in man. J Prosthet Dent 1975; 34: 456-462.

6. Horner K, Drage N, Brettle D S. 21st century imaging. London: Quintessence Publishing Co. Ltd, 2008.

7. Verde M A, Morgano S M. A dual-purpose stent for the implant-supported prosthesis. J Prosthet Dent 1993; 69: 276-280.

8. Chiapasco M, Zaniboni M, Boisco M. Augmentation procedures for the rehabilitation of deficient edentulous ridges with oral implants. Clin Oral Implants Res 2006; 17 (Suppl): 136-159.

9. Triplett R G, Schow S R. Autologous bone grafts and endosseous implants: complementary techniques. Int J Oral Maxillofac Surg 1996; 54: 486-494.

10. Chiapasco M, Abati S, Romeo E, Vogel G. Clinical outcome of autogenous bone blocks or guided bone regeneration with e-PTFE membranes for the reconstruction of narrow edentulous ridges. Clin Oral Implants Res 1999; 10: 278-288.

11. Raghoebar G M, Batenburg R H, Vissink A, Reintsema H. Augmentation of localized defects of the anterior maxillary ridge with autogenous bone before insertion of implants. J Oral Maxillofac Surg 1996; 54: 1180-1185.

12. Donos N, Mardas N, Chadha V. Clinical outcomes of implants following lateral bone augmentation: systematic assessment of available options (barrier membranes, bone grafts, split osteotomy). J Clin Periodontol 2008; 35: 173-202.

13. Tonetti M S, Hämmerle C H F and on behalf of the European Workshop on Periodontology Group C. Advances in bone augmentation to enable dental implant placement: Consensus Report of the Sixth European Workshop on Periodontology. J Clin Periodontol 2008; 35: 168-172.

14. Rocchietta I, Fontana F, Simion M. Clinical outcomes of vertical bone augmentation to enable dental implant placement: A systematic review. J Clin Periodontol 2008; 35: 230-242.

15. Chiapasco M, Casentini P, Zaniboni M. Bone augmentation procedures in implant dentistry. Int J Oral Maxillofac Implants 2009; 24(Suppl): 237-259.

16. Esposito M, Grusovin M G, Felice P, Karatzopoulos $G$, Worthington H V, Coulthard P. Interventions for replacing missing teeth: horizontal and vertical bone augmentation techniques for dental implant treatment. Cochrane Database Syst Rev 2009; 7: CD003607.

17. Barber A J, Butterworth C J, Rogers S N. Systematic review of primary osseointegrated dental implants in head and neck oncology. Br J Oral Maxillofac Surg 2011; 49: 29-36.

18. Jivraj $S$, Chee $W$. Treatment planning of implants in the aesthetic zone. Br Dent J 2006; 201: 77-89.

19. Chen S T. Immediate implant placement post extrac tion without flap elevation. J Periodontol 2009; 80: 163-172.

20. Takei H H, Azzi R R. Periodontal plastic and esthetic dentistry. In Newman M G, Takei H H, Carranza F A (eds). Clinical periodontology, 9th ed. pp 851-875. Philadelphia: WB Saunders, 2002

21. Hertel R C, Blijdorp P A, Baker D L. A preventive mucosal flap technique for use in implantology. Int J Oral Maxillofac Implants 1993; 8: 452-458.

22. Palacci P. Optimal implant positioning and softtissue considerations. Oral Maxillofac Surg Clin North Am 1996; 8: 445-452.

23. Harris R J. A comparative study of root coverage obtained with guided tissue regeneration utilizing a bioabsorbable membrane versus the connective tissue with partial thickness double pedicle graft. J Periodontol 1997; 68: 779-790.

24. Bruno J F. Connective tissue graft technique assuring wide root coverage. Int J Periodontics Restorative Dent 1994; 14: 126-137.

25. Burkhardt $R$, Joss A, Lang N P. Soft tissue dehiscence coverage around endosseous implants: A prospective cohort study. Clin Oral Implants Res 2008; 19: 451-457.

26. Pontoriero R, Tonelli M P, Carnevale G, Mombelli A, Nyman S R, Lang N P. Experimentally induced periimplant mucositis. A clinical study in humans. Clin Oral Implants Res 1994; 5: 254-259.

27. Lindhe J, Berglundh T, Ericsson I, Liljenberg B Marienello C P. Experimental breakdown of periimplant and periodontal tissues. A study in the beagle dog. Clin Oral Implants Res 1992; 3: 9-16.

28. Lang N P, Berglundh T. Working Group 4 of Seventh European Workshop on Periodontology. Periimplant diseases: where are we now? Consensus of the Seventh European Workshop on Periodontology. J Clin Periodontol 2011; 38(Suppl 11): 178-181. 